03

\title{
Динамика струй при изотермическом пленочном течении
}

\author{
(C) А.В. Бобылев ${ }^{1,2}$, В.В. Гузанов ${ }^{1,2}$, С.М. Харламов ${ }^{1,2}$, А.З. Квон ${ }^{1,2}$, \\ Д.М. Маркович ${ }^{1,2}$
}

${ }^{1}$ Институт теплофризики им. С.С. Кутателадзе СО РАН, Новосибирск

${ }^{2}$ Новосибирский государственный университет

E-mail: bobylev@itp.nsc.ru

Поступило в Редакцию 21 марта 2017 г.

Проведен анализ осредненных полей толщины изотермической вертикально стекающей пленки жидкости, полученных методом лазерно-индуцированной флуоресценции. Выбор минимального значения интервала времени осреднения, при котором волновое движение оказывается полностью осредненным, позволил наблюдать динамику струй в поперечном направлении. Обнаружено, что преобладающими структурами на поверхности пленки при числе Рейнольдса $\operatorname{Re}>50$ являются короткоживущие струи, которые представляют собой цепочки не менее чем из 5-8 волн, имеющих близкие значения поперечной координаты.

DOI: 10.21883/PJTF.2017.15.44866.16784

Последние достижения в области исследования волновых режимов течения пленки жидкости связаны с описанием сценариев перехода от двумерных (2D) к трехмерным (3D) волнам, а также с описанием движения уединенных 3D-волн и некоторых особенностей механизмов их взаимодействия. Вместе с тем развитие волновых режимов со временем с последующим достижением развитого 3D-волнового режима, а также универсальные критерии, указывающие на то, что волновой режим можно считать полностью развитым, до сих пор не совсем ясны даже для случая вертикально стекающей пленки жидкости.

Обзор экспериментальных работ по классификации режимов пленочного течения на больших расстояниях свыше $1 \mathrm{~m}$ от начала течения обнаруживает неопределенность в интерпретации статистических характеристик волнового движения, полученных различными авторами. Так, в работе [1] указывается на отсутствие стабилизации волнового движения 
на расстоянии вплоть до $2 \mathrm{~m}$ от начала течения при числе Рейнольдса $\operatorname{Re}>75$, тогда как в [2,3], напротив, утверждается, что на том же или меньшем расстоянии волновые характеристики стабилизируются для всех чисел Рейнольдса вплоть до значений $R e<250-375$ в случае пленки воды. Одной из причин такой неопределенности является то, что в большинстве экспериментов использовались методы локальных измерений волновых характеристик пленки, что не позволяет четко различать 2D- и 3D-волны. Другим объяснением может служить явление формирования струйного течения в процессе перехода от 2Dк 3D-волнам, обнаруженное в $[4,5]$ при рассмотрении осредненных полей толщины пленки жидкости. В этих работах показано, что в области перехода от 2D- к 3D-волнам локальные расходы жидкости и волновые характеристики пленочного течения могут сильно отличаться в поперечном направлении на характерных расстояниях порядка $1 \mathrm{~cm}$. Отметим, что впервые развитие вниз по потоку струйного течения было отмечено в работе [2].

Явление формирования струй ранее никогда не принималось в расчет при описании переходных процессов от 2D- к 3D-волновому режиму в стекающей пленке жидкости. Вместе с тем в [4-6] показано, что струи встречаются в области перехода от 2D- к 3D-волнам в диапазоне $15<\operatorname{Re}<100$, при этом происходит изменение положения струй в поперечном направлении, изменяется их амплитуда, реализуются сценарии их слияния и распада. Из-за сложности волновой структуры при описании таких режимов широко используются статистические методы. Стандартный подход при вычислении статистических характеристик предусматривает улучшение статистики путем увеличения длины выборки. Однако применительно к анализу пленочных течений такой подход может приводить к потере информации о медленных процессах перестройки осредненной структуры течения со временем. В этой связи возникает вопрос о некотором минимальном значении интервала времени осреднения волнового движения, когда, с одной стороны, можно уверенно говорить о струйном характере осредненного течения, а с другой - рассматривать струйное течение в динамике. В данной работе предложено проводить осреднение полей толщины пленки по промежутку времени, за который среднеквадратическое отклонение толщины пленки становится меньше некоторой пороговой величины, например погрешности измерения.

Письма в ЖТФ, 2017, том 43, вып. 15 
Эксперименты проводились на прозрачной вертикальной пластине размером $45 \times 140 \mathrm{~cm}($ см. $[5,6])$. Исследовались режимы пленочного течения с естественной волновой эволюцией и искусственно возбуждаемыми волнами на воде и водоглицериновых растворах (ВГР) в диапазоне чисел Рейнольдса $5<\operatorname{Re}<100$ и чисел Капицы $1100 \leqslant \gamma \leqslant 3700$, где $\gamma=\sigma \rho^{-1} v^{-4 / 3} g^{-1 / 3}, \sigma-$ поверхностное натяжение, $\rho-$ плотность, $v-$ кинематическая вязкость, $g$ - ускорение свободного падения. Количественные данные о полях локальных толщин пленки в различных областях течения вниз по потоку были получены методом лазерно-индуцированной флуоресценции (ЛИФ). Съемка каждой реализации длительностью $2 \mathrm{~s}$ проводилась скоростной камерой $\mathrm{c}$ частотой $1 \mathrm{kHz}$ и временем экспозиции $1 \mathrm{~ms}$ на площадке $13 \times 13 \mathrm{~cm}$ с разрешением $0.13 \mathrm{~mm}$ на пиксель. Время записи реализации было ограниченно техническими возможностями системы измерения. Общая картина течения регистрировалась независимо от ЛИФ-измерений методом теневой фотографии.

Для каждого исследуемого режима вычислялись осредненные по времени поля толщины пленки. Для режимов $\mathrm{Re}>10-20$ в области перехода от 2D- к 3D-волнам и далее вниз по течению на осредненных полях было зафиксировано формирование струй. Наблюдения показали, что в общем случае струи эволюционируют вниз по потоку. Вместе с тем характерное значение времени, в течение которого происходит перестройка струйного течения, для каждого конкретного режима остается неизвестным. Соответственно при осреднении полей толщины по времени важным параметром становится некоторое минимальное пороговое значение интервала времени осреднения $t_{a v}$, при котором волновое движение полностью усредняется, и можно наблюдать динамику только средних значений толщины пленки. Занижение значения $t_{a v}$ не позволяет полностью осреднить волновое движение, а значительное завышение этого параметра может приводить к потере информации о достаточно медленных в сравнении со временем прохождения волн процессах перестройки течения. В качестве примера на рис. 1,a приведено осредненное поле локальных толщин пленки жидкости за период времени $t_{a v}=2 \mathrm{~s}$. По координате $x$ отложено расстояние от начала течения. На рисунке четко просматривается струйный характер осредненного течения. При этом по краям поля наблюдаются устойчивые в границах записи реализации струи. В центральной части на рис. $1, a$ наблюдается область с повышенной толщиной, ширина

Письма в ЖТФ, 2017, том 43, вып. 15 



Рис. 1. Перестройка течения при $t_{a v}=0.73 \mathrm{~s}$. Вода, $\operatorname{Re}=24, F=14 \mathrm{~Hz} . a-$ осредненное поле толщины при $t_{a v}=2 \mathrm{~s} ; b-$ изменение $\sigma$ на гребне и во впадине, в точках 1 и 2 , с ростом $t_{a v}$, пунктирными линиями иллюстрируется выбор $t_{a v}$ по пороговому значению $\sigma=10 \mu \mathrm{m} ; c, d$ - эволюция осредненных по $t_{a v}=0.73 \mathrm{~s}$ профилей толщины со временем в поперечных сечениях I и II.

Письма в ЖТФ, 2017, том 43, вып. 15 


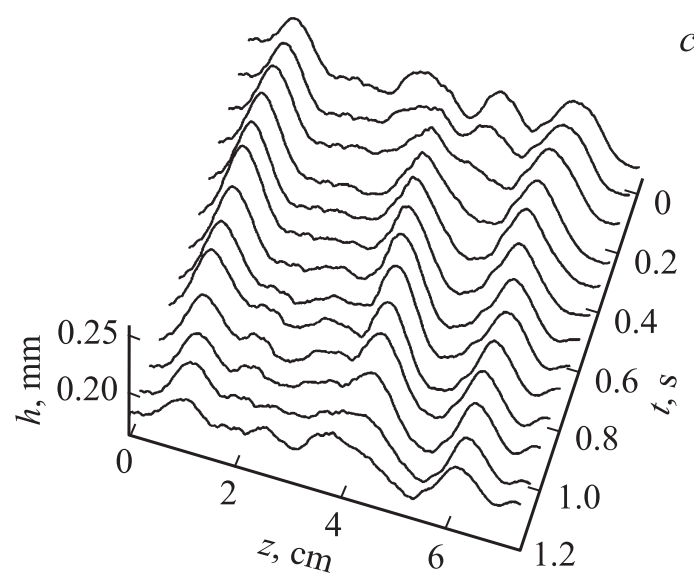

$c$

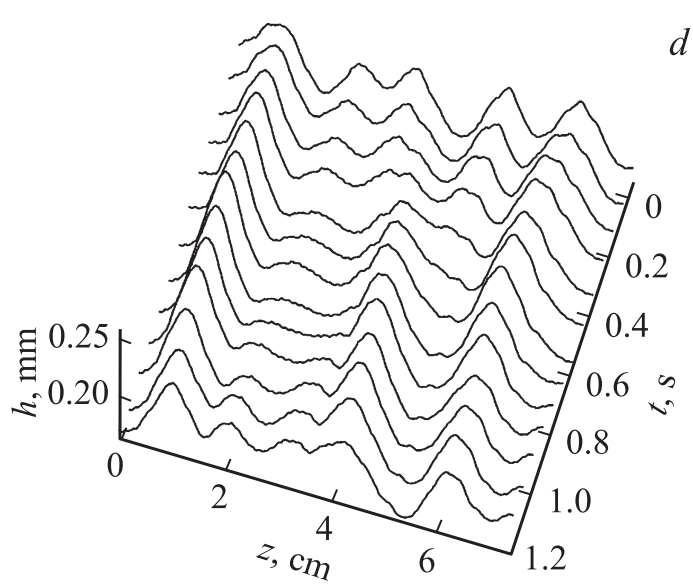

Рис. 1 (продолжение).

которой значительно больше характерной ширины устойчивой струи. Как показывают теневые наблюдения в этой области течения, возможно как перемещение струи в поперечном направлении, так и слияние двух соседних струй. Динамику движения струй в этой области можно наблюдать с применением определенного значения интервала

Письма в ЖТФ, 2017, том 43, вып. 15 
времени осреднения $t_{a v}$, который можно выбирать следующим образом. В указанных на рис. 1, $a$ точках 1 и 2 , соответствующих гребню устойчивой струи и устойчивой впадине между струй, путем сдвига интервала осреднения в границах записи реализации с использованием заданного значения $t_{a v}$ рассчитывались средние значения толщины. По полученному массиву осредненных толщин рассчитывалось среднеквадратическое отклонение $\sigma$ осредненной толщины для заданного значения $t_{a v}$. Расчет последовательно проводился для значений $t_{a v}$ в диапазоне от 0.03 до $2 \mathrm{~s}$ (рис. $1, b$ ). Как следует из графика, с ростом $t_{a v}$ значения $\sigma$, хотя и в разной степени, но затухают как на гребне, так и во впадине осредненного поля толщины. Для всех исследованных режимов $\sigma$ становится меньше характерного значения погрешности измерения толщины, связанной в основном с шумами CCD-камеры $\sim 10 \mu \mathrm{m}$ уже при $t_{a v}>0.5-1 \mathrm{~s}$ в зависимости от режима течения. В примере на рис. $1, b$ графически продемонстрирован выбор $t_{a v}=0.73 \mathrm{~s}$, обусловленный пороговым значением $\sigma$, при котором как для гребня, так и для впадины $\sigma$ принимало значения, меньшие $10 \mu \mathrm{m}$. На рис. $1, c, d$ приведены графики профилей осредненной толщины в поперечных сечениях I и II (см. рис. $1, a)$ с установленным $t_{a v}=0.73 \mathrm{~s}$. По оси $t$ отложено смещение $t_{a v}$ относительно начала записи реализации. Как следует из графиков, в центральной области происходит перестройка течения, выраженная в слиянии двух струй в одну за общее время $t \approx 1.2 \mathrm{~s}$. Как следствие, область в центре кадра на рис. 1, $a$ выглядит размыто, поскольку за время $t=2 \mathrm{~s}$ процесс слияния струй осредняется.

Как было указано в [4], при достаточно больших $\operatorname{Re}>40-60$ развитие струй носит немонотонный характер. В результате при больших $t_{a v} \approx 2 \mathrm{~s}$ на осредненном поле толщины структура струйного течения выражена крайне слабо (рис. 2,a). Однако при выбоpe $t_{a v}=0.64 \mathrm{~s}$, полученного с использованием порогового значения $\sigma \sim 10 \mu \mathrm{m}$, наблюдается струйный характер течения (рис. 2,b). При этом прослеживается последовательное смещение струй в поперечном направлении, а также процесс слияния соседних струй. Для сравнения на рис. $2, b$ пунктирной линией представлен профиль толщины, осредненной по всей реализации. Из графика видно, что при большом времени осреднения амплитуда струй существенно занижается, практически в 2 раза. Отметим, что для всех исследованных режимов полученное описанным выше методом значение $t_{a v}$ оказа-

Письма в ЖТФ, 2017, том 43, вып. 15 


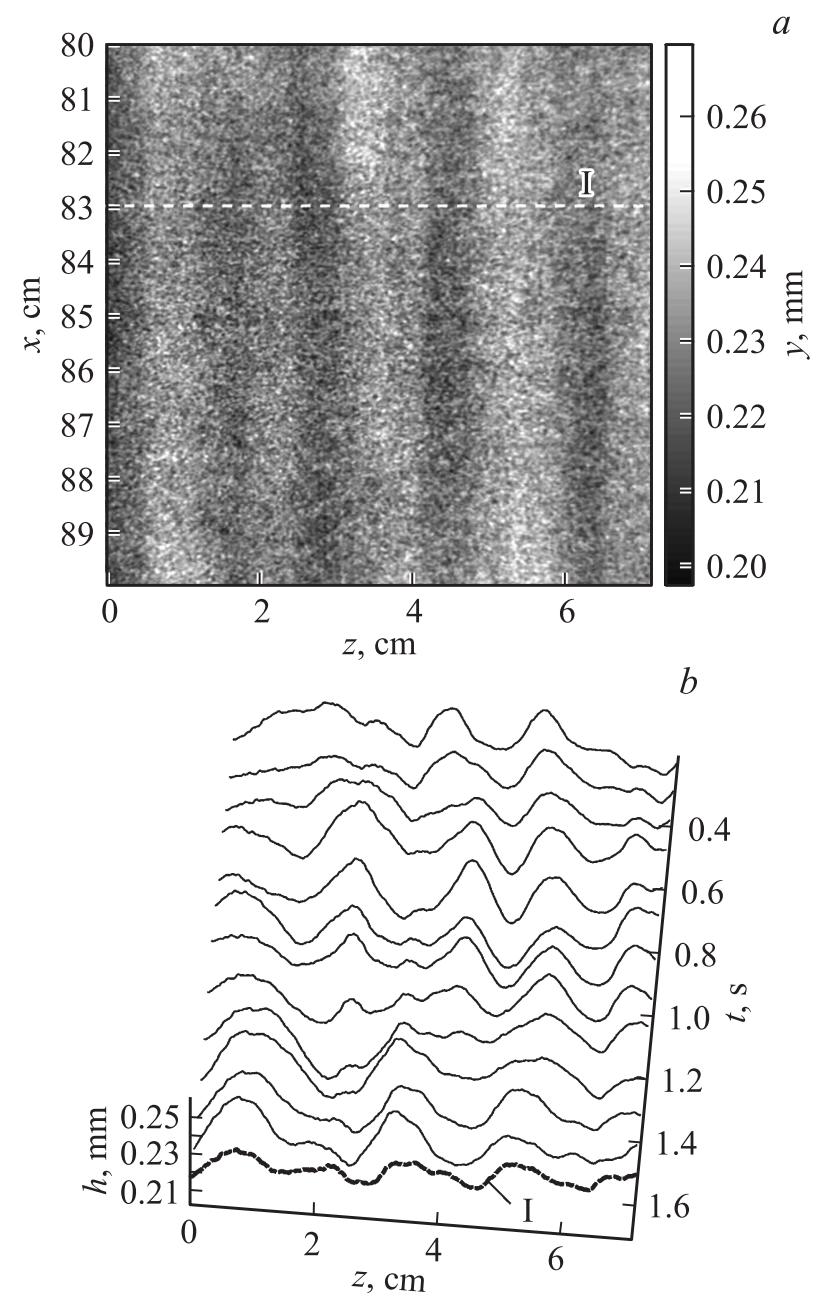

Рис. 2. Перестройка струйного течения при $t_{a v}=0.64 \mathrm{~s}$. Вода, $\operatorname{Re}=55$, $F=17 \mathrm{~Hz} . a-$ осредненное поле толщины при $t_{a v}=2 \mathrm{~s} ; b-$ эволюция осредненного по $t_{a v}=0.64 \mathrm{~s}$ профиля толщины со временем в поперечном сечении I. Жирной штрихпунктирной линией представлен профиль толщины I, осредненный за интервал $t_{a v}=2 \mathrm{~s}$.

Письма в ЖТФ, 2017, том 43, вып. 15 
лось в разы меньше времени записи всей реализации, что позволяет в динамике рассматривать движение струй на осредненных полях толщины.

Детальное рассмотрение динамики движения струй с использованием минимального значения $t_{a v}$ показало, что при больших $\operatorname{Re}>40-60$, после перехода к $3 D$-волновому движению, в основном наблюдаются активно перемещающиеся в поперечном направлении короткоживущие струи. Минимальное время жизни таких струй в 5-8 раз превышает характерное значение времени прохождения волн, оцененное по максимуму в спектральной плотности мощности [7]. Таким образом, можно говорить об образовании и движении на поверхности пленки структур, представляющих собой цепочки, состоящие минимум из 5-8 волн, положение которых в поперечном направлении изменяется слабо за время жизни этой цепочки. Хаотические перемещения и слияния таких структур приводят к существенному подавлению струйной картины на осредненных полях толщины при больших временах осреднения. С ростом вязкости жидкости процессы слияния и перемещения струй в поперечном направлении проявляются реже и на большем расстоянии от начала течения, т. е. струйное течение становится более стабильным. К значительной стабилизации положения струй в поперечном направлении и, как следствие, увеличению длины цепочек волн приводит возбуждение двумерных волн в начальной области течения. При этом характерные амплитуды струй возрастают на 20-30\% в сравнении со случаем естественной волновой эволюции. Последнее обстоятельство может быть использовано для управления течением и процессами тепло- и массообмена при пленочном течении жидкости.

Работа выполнена при финансовой поддержке Российского фонда фундаментальных исследований, проект № 15-01-06702-а.

\section{Список литературы}

[1] Ishigai S. et al. // Bull. JSME. 1972. V. 21. N 83. P. 594.

[2] Salazar R.P., Marschall E. // Int. J. Multiphase Flow. 1978. V. 4. N 4. P. 405.

[3] Takamasa T., Kobayashi K. // Int. J. Multiphase Flow. 2000. V. 26. N 9. P. 1493.

[4] Алексеенко С.В., Гузанов В.В., Маркович Д.М., Харламов С.М. // Письма в ЖТФ. 2012. Т. 38. В. 16. С. 16. 
[5] Kharlamov S.M., Guzanov V.V., Bobylev A.V. et al. // Phys. Fluids. 2015. V. 27. N 11. P. 114106

[6] Алексеенко С.В., Бобылев А.В., Гузанов В.В. и др. // Письма в ЖТФ. 2014. T. 40. B. 22. C. 97.

[7] Гузанов В.В., Бобылев А.В., Квон А.З. и др. // Письма в ЖТФ. 2016. Т. 42. B. 5. C. 24 .

Письма в ЖТФ, 2017, том 43, вып. 15 